\title{
DUPONT, CHRISTIAN. PHENOMENOLOGY IN FRENCH PHILOSOPHY: EARLY ENCOUNTERS. 338 PP. DORDRECHT, 2014: SPRINGER
}

\author{
Alan Hernández Marcelo \\ Universidad Antonio Ruiz de Montoya, Perú
}

El texto de Christian Dupont es la publicación de su tesis doctoral presentada en la Universidad de Notre Dame en 1997. Para la presente edición de la serie Phaenomenologica, auspiciada por los Archivos-Husserl de la Universidad Católica de Lovaina, se realizó una edición de estilo, pero sin alterar sustancialmente el contenido. Por lo tanto, el texto debe leerse dentro del contexto de la formación intelectual del autor y de su intento por ofrecer al público estadounidense un estudio sobre la recepción francesa de la fenomenología.

En Phenomenology in French Philosophy. Early Encounters, Dupont defiende la tesis de la presencia de dos recepciones antagónicas e independientes de la fenomenología en Francia, a saber: la de los filósofos y la de los pensadores religiosos. La novedad del detallado análisis histórico que realiza el autor es la contribución de los pensadores religiosos franceses a la recepción de la fenomenología en su país, un aspecto totalmente ignorado por la escasa investigación sobre el tema. A diferencia de lo que sucedió con la recepción filosófica, los pensadores religiosos recibieron la fenomenología por una vía distinta. La recepción de la fenomenología en el fuero religioso dependería principalmente de la asociación con las ideas fenomenológicas de Henri Bergson y Maurice Blondel, bautizados por Dupont como los precursores de la fenomenología en Francia. La originalidad de los enfoques de estos filósofos le dio forma definitiva al pensamiento francés y lo preparó para la recepción del movimiento fenomenológico (p. 93). El vínculo entre los precursores de la fenomenología y los pensadores religiosos radica en su salida de la tradición cartesiana.

Por un lado, en lo concerniente a la recepción filosófica de la fenomenología (1910-1939), Dupont expone cuatro fases de dicha recepción como estrategia para organizar las variadas interpretaciones que hicieron los filósofos que más contribuyeron para introducir la fenomenología en Francia. Es importante resaltar aquí el rol que jugaron los intelectuales que migraron de Europa del Este después de la Primera Guerra Mundial porque fueron ellos el medio a través del cual ingresó la fenomenología al mundo académico francés. Las fases de dicha recepción filosófica ofrecen un camino progresivo de comprensión cada vez más preciso y completo 
de la fenomenología hasta su apropiación original y crítica. Este apartado revela la tendencia de los filósofos por asimilar la fenomenología husserliana con la tradición cartesiana (p. 103).

Por otro lado, en relación a la recepción religiosa, Dupont distingue dos etapas. La primera etapa (1901-1929) se caracteriza por una apropiación de las ideas fenomenológicas de Bergson y Blondel. En ese sentido, los dos autores analizados en este apartado, Édouard Le Roy y Pierre Rousselot, son considerados como los precursores de la fenomenología en el círculo de los pensadores religiosos. Ellos prepararon a la siguiente generación de pensadores religiosos franceses para comprender y apreciar la fenomenología de Husserl (p.313). En la segunda etapa (1929-1939), los primeros pensadores religiosos centraron su atención en la fenomenología de la religión de Scheler. En general, consideraron que el movimiento fenomenológico ofrecía una alternativa al racionalismo cartesiano e intentaban vincular la fenomenología con el tomismo en un esfuerzo por renovar el pensamiento escolástico.

En conclusión, el estudio pormenorizado de la inicial recepción de la fenomenología en Francia anterior a 1939 frente a la escasa atención proporcionada a dicha recepción, por un lado, y la novedad de la contribución de los pensadores religiosos frente a la ceguera respecto a ellos, por otro, le otorga un enorme valor a esta obra y la convierte en un referente ineludible para todos los estudios posteriores relacionados con esta temática. Asimismo, el tratamiento del vínculo entre el pensamiento religioso y el movimiento fenomenológico en la inicial recepción de la fenomenología en Francia, sirve para brindar un contexto adecuado para la interpretación de los contemporáneos enfoques franceses que integran fenomenología y teología. 